\title{
INVESTIGATIONS ON THE ORIGIN AND EFFECT OF ANOMALOUS RAFTING
}

\author{
Horst Biermann, Ulrich Tetzlaff, Haël Mughrabi, Berthold von Grossmann ${ }^{1}$, Stefan Mechsner ${ }^{2}$ and Tamas Ungár ${ }^{3}$ \\ Institut für Werkstoffwissenschaften, Lehrstuhl I, Universität Erlangen-Nürnberg, \\ Martensstr. 5, D-91058 Erlangen, Fed. Rep. Germany \\ ${ }^{1}$ now at: AUDI AG, D-85045 Ingolstadt, Fed. Rep. Germany \\ ${ }^{2}$ now at: Siemens AG, D-97076 Würzburg, Fed. Rep. Germany \\ ${ }^{3}$ Institute for General Physics, Eötvös University, P. O. Box 32, H-1518 Budapest, Hungary
}

\begin{abstract}
$\underline{\text { Abstract }}$
Anomalous rafting is a morphological transformation of the phases $\gamma$ and $\gamma^{\prime}$ occurring in monocrystalline nickel-base superalloy turbine blades which is observed under the surface of the turbine blades after service. The origin of anomalous rafting is discussed, based on microstructural investigations of turbine blades before and after service and of laboratory samples after shot peening and ageing. Microscopical investigations are completed with microhardness and X-ray diffraction measurements. Residual macrostresses and long-range internal microstresses are discussed as driving forces of anomalous rafting, induced by the plastic deformation of subsurface layers of the material, e.g. during peening. Finally, the effect of anomalous rafting is discussed on the basis of fatigue and creep experiments.
\end{abstract}

\section{Introduction and Objectives}

Rafting of monocrystalline nickel-base superalloys has been investigated experimentally and modcled in detail in recent ycars $[1,2]$. The change of the originally cuboidal shape of the $\gamma^{\prime}$ precipitates towards a $\gamma / \gamma^{\prime}$ plate structure occurs at temperatures above about $1150 \mathrm{~K}$ during deformation or in samples predeformed at a lower temperature during subsequent (stress-free) ageing treatments [35]. In the regime of plastic deformation above plastic strains of $\varepsilon_{\mathrm{pl}}=$ 0.001 to 0.002 , the orientation of the plate structure depends on the lattice mismatch $\delta$ ( $\delta$ is the relative difference of the lattice parameters of the two phases $\gamma^{\prime}$ and $\gamma$ ) and on the direction of the externally applied stress $\sigma$. Detailed experimental investigations have shown that the modification of the internal stress state during deformation is responsible for the type of rafting observed, i.e. whether the plate structure has an orientation parallel or perpendicular to the stress axis [3-6]. Thus, it was shown that the type of rafting is governed strongly by the sign of the plastic deformation [3-6].

In the hot regions of the airfoils of turbine blades, a $\gamma / \gamma^{\prime}$ raft structure develops which has an orientation perpendicular to the stress axis [7-9], because the lattice misfit of technically applied turbine blade superalloys is negative at the high service temperatures, and the external stress axis acting on a blade during service is tensile due to the centrifugal stresses. In regions near the surface, however, a different microstructure, called anomalous raft structure. with an orientation of the plates parallel to the surface has been found repeatedly $[7,8,10,11]$ which was in some cases attributed to the influence of a surface coating $[10,11]$.

In the present work, we consider different types of anomalous rafting, occurring in

- real turbine blades during service,

- initially unused turbine blades during ageing and

- shot-peened laboratory samples during ageing.

The origin of anomalous rafting occurring in different cases is discussed on the basis of microhardness and microfocus $\mathrm{X}$-ray diffraction investigations. Furthermore, its effect on the high-temperature strength properties of nickel-base superalloys is investigated in fatigue and creep experiments which are part of a more extended study of the influence of different $\gamma / \gamma^{\prime}$ raft structures on mechanical high-temperature properties [12-15]. 


\section{Experimental}

\section{Material}

Turbine blades Three different NiAl-coated turbine blades made of the nickel-base superalloy CMSX-6 with orientations near [001] were available $([001]$ is defined in the following to be that $\langle 100\rangle$ direction which is nearly parallel to the turbine blade or specimen axis, respectively). Before the (developmental) coating treatment, the blades were peened. The following investigations were performed on these standard two-stage heat treated blades: i) one turbinc blade was studicd in the as-manufactured state. In addition, sections of this turbine blade were aged under vacuum at temperatures of $1273 \mathrm{~K}$ and $1323 \mathrm{~K}$, respectively, for times between $200 \mathrm{~h}$ and $1000 \mathrm{~h}$. ii) The other two turbine blades were exposed to accelerated mission tests in a ground-based test engine for different durations (for details see references $[8,9]$; it has to be noted that the total test times of service in the engine tests were different. The microstructure of the turbine blade with the higher service time was described in detail earlier [8,9]). The engine tests were performed under continuous maximum temperature conditions with a higher temperature than under normal operation of the engine.

Laboratory samples The deformation experiments (i.e. shot peening, fatigue and creep tests) were carried out on monocrystalline samples of the nickel-base superalloys SRR 99. The rods were supplied in the standard state after a two-stage heat treatment. More details are given in references $[14,15]$.

\section{Shot peening}

Shot peening was applied on monocrystalline samples of the nickel-base superalloy SRR 99 with an orientation near [001], $\mathrm{cf}$. reference [16]. Electrolytically polished rods of $10 \mathrm{~mm}$ diameter and $150 \mathrm{~mm}$ length were peened with steel shot of specification S170, an Almen intensity of $0.42 \mathrm{mmA}$ and a peening coverage of $200 \%$. After peening, a thin surface layer of about $5 \mu \mathrm{m}$ was removed electrolytically in order to avoid iron contamination. Subsequently, sections of the rods were aged in vacuum at temperatures between $1173 \mathrm{~K}$ and $1353 \mathrm{~K}$ for times between $4 \mathrm{~h}$ and $300 \mathrm{~h}$. The microstructure of these samples was investigated by scanning electron microscopy (SEM).

After preliminary ageing experiments performed on the shot-peened rods, samples for mechanical fatigue and creep tests were shot-peened under the same conditions as the rods. Some samples were aged in vacuum for $24 \mathrm{~h}$ at a temperature of $1323 \mathrm{~K}$ and some for $200 \mathrm{~h}$ at $1223 \mathrm{~K}$, respectively. These conditions were found to give an "anomalous" raft structure, as will be shown later. The second heat treatment was performed to obtain anomalous rafts without strong coarsening of the $\gamma^{\prime}$ particles in the bulk of the samples (the ageing conditions are mentioned in the corresponding sections appropriately). Most peened and aged samples showed a recrystallized surface layer, as will be discussed later.

\section{Microcharacterization}

Scanning electron microscopy Sections of the turbine blades and of the laboratory specimens were cut parallel to $\{100\}$ lattice planes and polished mechanically up to a final diamond powder grade of $1 \mu \mathrm{m}$. Subsequently, the sections were etched with a solution of $\mathrm{H}_{2} \mathrm{O}, \mathrm{HCl}, \mathrm{MoO}_{3}$ and $\mathrm{HNO}_{3}$ which etches preferentially the $\gamma^{\prime}$ phase and finally sputtered with gold. Scanning electron microscopy was performed at an acceleration voltage of $20 \mathrm{kV}$ in secondary electron contrast.

Microhardness testing The microhardness after Vickers (HV0.05) was determined as a function of the distance from the surface on different shot-peened samples of the nickel-base superalloy SRR 99. One sample was investigated before ageing, two samples after ageing under conditions which produced an "anomalous" raft structure ( $24 \mathrm{~h}$ at $1323 \mathrm{~K}$ and $100 \mathrm{~h}$ at $1273 \mathrm{~K}$ ), and one after ageing, but without rafting ( $24 \mathrm{~h}$ at $1273 \mathrm{~K}$ ).

$\underline{X-r a y}$ diffraction The shift of the centre of gravity of X-ray peak profiles indicates the effect of residual stresses arising from shot peening which will be called macrostresses in the following. Such peening stresses are of biaxial compressive character directly under the surface of peened samples. They decrease with increasing distance to the surface. In addition to the peening (macro-)stresses, longrange internal microstresses acting between the two phases $\gamma$ and $\gamma^{\prime}$ were investigated. These microstresses which were repeatedly found (e.g. after creep deformation [17] or in turbine blades after service $[8,9])$ cause counteracting shifts of the individual subprofiles of the phases $\gamma$ and $\gamma^{\prime}$. Thus, the peak profiles are asymmetric and consist of two subprofiles. The asymmetry is of opposite character for peak profiles measured parallel and perpendicular to the deformation axis.

In order to study X-ray peak profiles of the samples with adequate (high) lateral resolution, a new microfocus synchrotron radiation $X$-ray diffraction technique was applied (for details see [18,19]). A monochromatic, focussed X-ray beam with a linc focus of $2 x$ $50 \mu \mathrm{m}^{2}$ (wavelength of the radiation $\lambda=0.06886 \mathrm{~nm}$ ) was used to study the local variation of the lattice parameter distributions under the surface of shot-peened samples before and after an ageing treatment $(24 \mathrm{~h}$ at $1323 \mathrm{~K})$. The samples were mounted with the line focus parallel to the outer shot-peened surface of the samples. In addition, complementary peak profiles were measured with a "conventional" double-crystal X-ray diffractometer (wavelength $\lambda=0.15406 \mathrm{~nm})$, cf. [17] which has a focal spot on the sample of about $0.5 \times 0.5 \mathrm{~mm}^{2}$.

\section{Deformation tests}

Fatigue Symmetrical total strain controlled fatigue tests were carried out at a temperature of $1223 \mathrm{~K}$ at two different total strain ranges of $\Delta \varepsilon_{t}=0.01$ and 0.008 . Reference samples were tested in the standard state after electropolishing at both strain ranges (samples A: $\Delta \varepsilon_{\mathrm{t}}=0.01$ and B: $\Delta \varepsilon_{\mathrm{t}}=0.008$ ). Additional samples were tested after different pretreatments: At the larger strain range, sample $\mathrm{C}$ was tested in the shot peened state after removal of a thin laycr by mechanical and clectrolytical polishing (approximately $10 \mu \mathrm{m}$ ) to remove the roughness; sample D was peened and aged for $24 \mathrm{~h}$ at $1323 \mathrm{~K}$. A thin surface layer of about $30 \mu \mathrm{m}$ was removed, but the sample still showed recrystallized grains on the surface. Samples E and F were aged for $200 \mathrm{~h}$ at $1223 \mathrm{~K}$. Subsequently, a layer of about $80 \mu \mathrm{m}$ was removed by electropolishing. These samples had "anomalous" rafts on the surface without recrystallized grains after polishing. Sample E was tested at the larger and $\mathrm{F}$ at the smaller strain amplitude, respectively. 
Creep Tensile creep tests were performed on shot-peened samples with a diameter of $3 \mathrm{~mm}$ under a constant stress of $200 \mathrm{MPa}$ at a temperature of $1273 \mathrm{~K}$ up to plastic strains of about $3 \%$. One undeformed reference sample and two shot peened samples after ageing at different conditions were investigated.

\section{Anomalous rafting in turbine blades}

Initial state

Already in the unused (peened and coated) state of a turbine blade of the superalloy CMSX-6, a small amount of anomalous directional coarsening with $\gamma / \gamma^{\prime}$ plates oriented parallel to the surface was observed beneath the interdiffusion zone between the $\mathrm{NiAl}$ coating and the bulk of the superalloy, see Fig. 1 .

\section{Anomalous rafting during service}

During service of the turbine blades in a test engine, a change of the $\gamma / \gamma^{\prime}$ microstructure occurred in the hot regions of the airfoil at the leading and trailing edges, and a "normal" $\gamma / \gamma^{\prime}$ raft structure developed with an orientation perpendicular to the [001] blade axis. Under the surface of the blade exposed to service for the shorter time, a completely different microstructure with "anomalous"

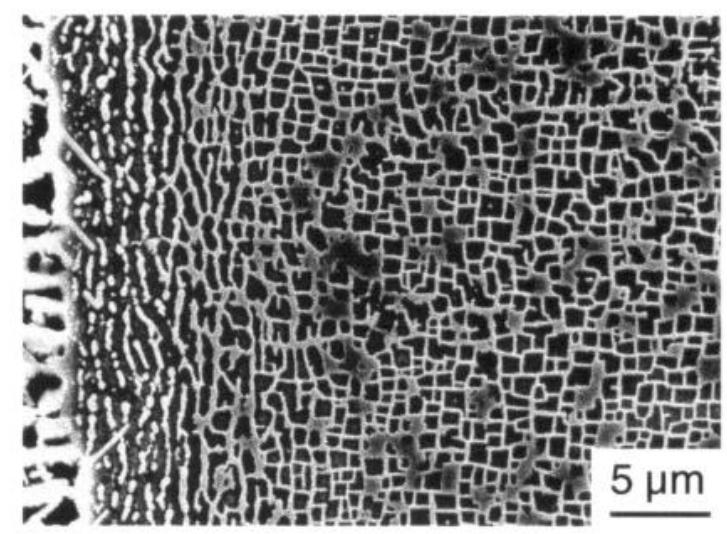

Figure 1: $\gamma / \gamma^{\prime}$ microstructure under the coating of an unused turbine blade, nickel-base superalloy CMSX-6. The interdiffusion zone under the aluminide coating is seen on the left. rafts, i.e. $\gamma / \gamma^{\prime}$ plates with an orientation parallel to the surface, was observed, as shown in Fig. 2. Such a microstructure, however, was not found in the second turbine blade with the double service time.

In addition to the anomalous rafts, a $\gamma^{\prime}$ enriched zone and topologically closed-packed phases appeared under the interdiffusion zone between aluminide coating and superalloy material. A more detailed description of the phases occurring under an aluminide coating was given earlier, e.g. by Moretto and Bressers [10].

\section{$\underline{\text { Rafting during stress-free ageing }}$}

The $\gamma / \gamma^{\prime}$ microstructure of a section of the unused turbine blade aged for $200 \mathrm{~h}$ at $1273 \mathrm{~K}$ is given in Fig. 3. The micrograph shows a $\gamma / \gamma^{\prime}$ plate structure in a region of up to $30 \mu \mathrm{m}$ thickness. The plates have an orientation parallel to that $\{100\}$ plane which has the smallest deviation from the outer surface of the turbine blade. Similar $\gamma / \gamma^{\prime}$ morphologies were also obtained after longer ageing times up to $1000 \mathrm{~h}$ or after ageing at a higher temperature $(1323 \mathrm{~K})$. However, it has to be mentioned that the plate structure shown in the figure was only observed under the convex surface of the aged turbine blade. Under the concave surface, separate $\gamma^{\prime}$ particles of cuboidal shape or coarsened due to the ageing treatment persisted up to the $\gamma^{\prime}$ enriched zone.

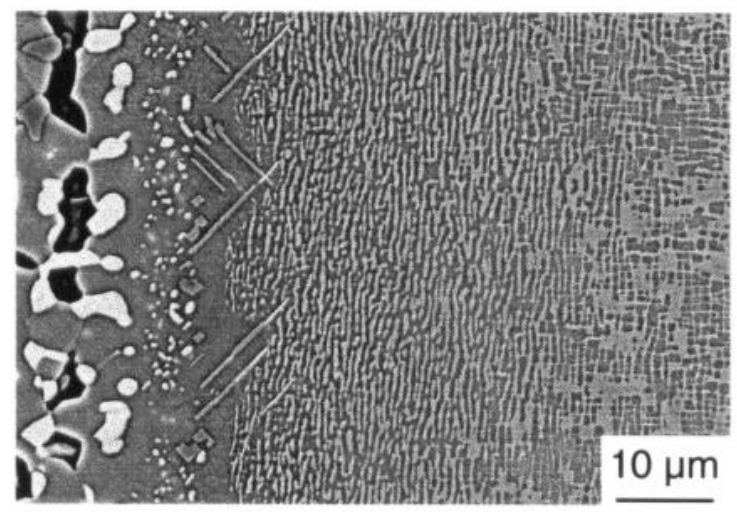

Figure 3: Microstructure of a specimen of the unused turbine blade (nickel-base superalloy CMSX-6) after ageing for $200 \mathrm{~h}$ at $1273 \mathrm{~K}$.

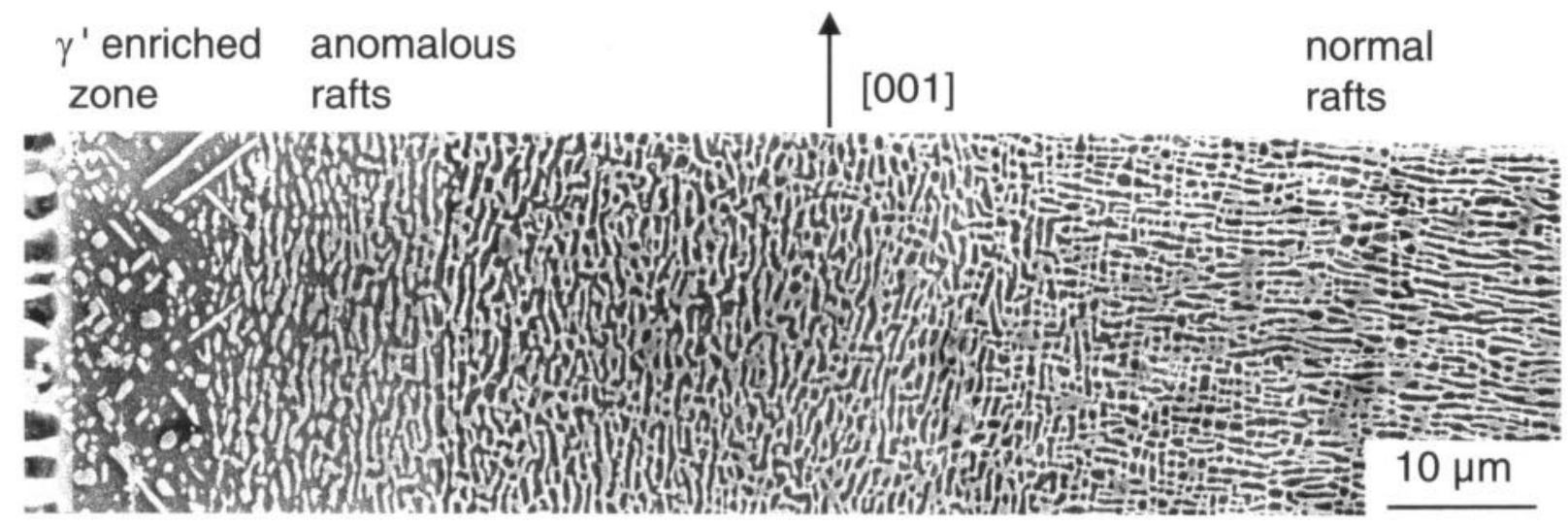

Figure 2: $\gamma / \gamma^{\prime}$ microstructure under the surface of a turbine blade after an accelerated mission test, nickel-base superalloy CMSX-6. On the left side, the interdiffusion zone under the $\mathrm{NiAl}$ coating is visible. Subsequently, a $\gamma^{\prime}$-enriched zone (with precipitates of $\mathrm{Cr}$-rich and topologically closed-packed phases) and a zone of "anomalous rafts" follow. 


\section{Shot-peened samples}

To obtain information on the origin of the microstructural changes occurring under the surfaces of nickel-base superalloy turbine blades during high-temperature applications, samples were investigated after shot peening and after shot peening and an additional ageing treatment. The results of microstructural investigations, microhardness tests and X-ray diffraction experiments are presented in the following sections.

\section{$\underline{\text { Rafting }}$}

After the ageing treatments, some of the samples showed a marked raft structure under the surface with an orientation of the $\gamma / \gamma^{\prime}$ plates parallel to the surface. Fig. 4 shows the microstructure of a sample aged for $24 \mathrm{~h}$ at $1323 \mathrm{~K}$. Directly at the surface, a layer of cellular recrystallization was obtained. Under this recrystallized layer, a region with $\gamma^{\prime}$ particles of unregular shape and a $\gamma / \gamma^{\prime}$ plate structure with an orientation parallel to the surface follow. In the bulk of the samples, cuboidal $\gamma^{\prime}$ particles were still present. Due to the ageing treatment, these $\gamma^{\prime}$ particles were coarsened. In those regions with an orientation of the surface of the rods parallel to $\{110\}$, the $\gamma / \gamma^{\prime}$ plates had orientations parallel to both corresponding $\{100\}$ lattice planes. A summary of the cases of anomalous rafting occurring during ageing for different times at different temperatures is given in Table I. It is clear that the process of rafting occurred after shorter times at higher temperatures (e.g. after $4 \mathrm{~h}$ at the highest temperature of $1353 \mathrm{~K}$ ) than at lower temperatures. At the lowest temperature of $1173 \mathrm{~K}$, only a small amount of rafts was found after $300 \mathrm{~h}$. This temperature dependence is clearly due to the thermal activation of diffusion which is necessary for rafting.
In order to decrease the width of the recrystallized region or to avoid recrystallization at all, different heating rates were applied: Some of the samples were put into the preheated furnace. Other samples were put into the cold furnace which was then heated at a rate of $50 \mathrm{~K}$ per hour to the ageing temperature with a holding time of $2 \mathrm{~h}$ at $1073 \mathrm{~K}$. These heating procedures, however, didn't yield a difference in the recrystallization behaviour.

Finally, the results obtained on an additional sample shall be mentioned: After shot peening, a surface layer of $50 \mu \mathrm{m}$ was removed before the ageing treatment $(24 \mathrm{~h}$ at $1323 \mathrm{~K})$. This polishing should remove the highly damaged outer material which is under the action of the largest compressive macrostresses after peening. As a result of this procedure, a rafted microstructure comparable to that shown in Fig. 4 was found after ageing, but no recrystallization was obtained.

Table I: Microstructure of shot-peened samples after ageing. The symbols " $\times$ " indicate the cases of a marked $\gamma / \gamma$ ' raft structure with an orientation parallel to the surface, " $\approx$ " the cases of a small microstructural change and "- the cases without rafting, respectively.

\begin{tabular}{lccccccc}
\hline & $4 \mathrm{~h}$ & $10 \mathrm{~h}$ & $24 \mathrm{~h}$ & $50 \mathrm{~h}$ & $100 \mathrm{~h}$ & $200 \mathrm{~h}$ & $300 \mathrm{~h}$ \\
\hline $1173 \mathrm{~K}$ & & & & & - & & $\approx$ \\
$1223 \mathrm{~K}$ & & & & & - & $\times$ & \\
$1273 \mathrm{~K}$ & - & - & - & $\approx$ & $\times$ & & \\
$1323 \mathrm{~K}$ & & $\times$ & $\times$ & & & & \\
$1353 \mathrm{~K}$ & $\times$ & & & & & & \\
\hline
\end{tabular}

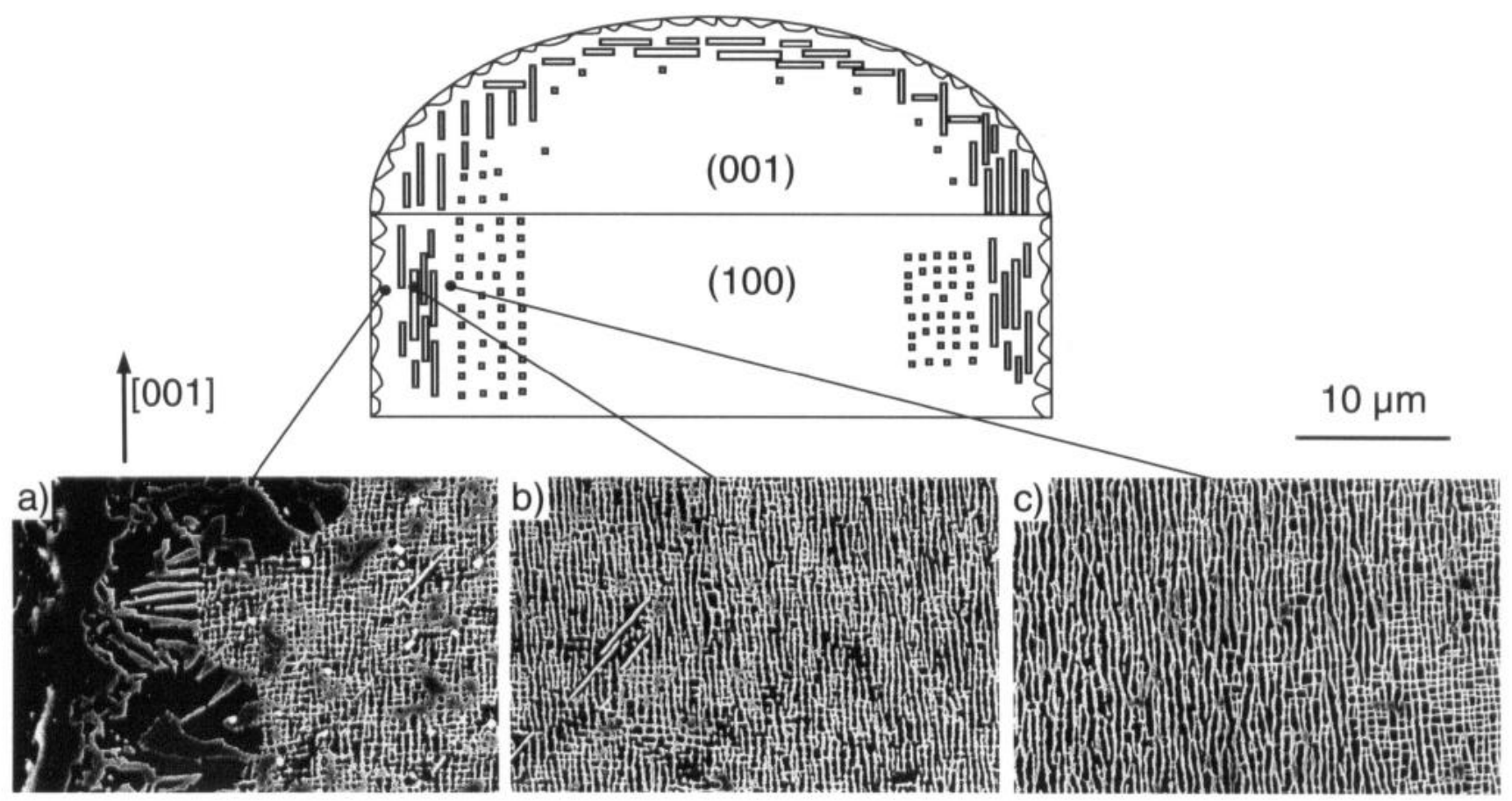

Figure 4: Microstructure of a shot-peened sample after ageing for $24 \mathrm{~h}$ at $1323 \mathrm{~K}$, nickel-base superalloy SRR 99 . The micrographs of the (100) section show a) cellular recrystallization directly under the surface, b) $\gamma / \gamma^{\prime}$ rafts with an orientation parallel to the surface and c) the transition from the rafts to cuboidal $\gamma^{\prime}$ precipitates at a distance of about $200 \mu \mathrm{m}$ from the surface. 


\section{Microhardness}

The courses of the microhardness under the surface of two shotpeened samples before and after ageing, respectively, are shown in Fig. 5. In the interior of the samples, an average hardness of 430 HV0.05 was obtained. An increase of the hardness under the surface was found prior to ageing, starting at a distance from the surface of about $200 \mu \mathrm{m}$ up to an average value of $600 \mathrm{HV} 0.05$ at a distance of $30 \mu \mathrm{m}$ from the surface. This increase can easily be explained to be a result of the peening treatment.

The results of microhardness tests obtained on a sample aged for $24 \mathrm{~h}$ at $1323 \mathrm{~K}$ are also shown in Fig. 5. An approximately constant value comparable to that of the undeformed interior of the material was found. The increase of hardness induced by shot peening vanished completely during the ageing procedure. A similar behaviour was also obtained after ageing at $1273 \mathrm{~K}$, irrespective of the duration of the ageing procedure $(24 \mathrm{~h}$ or $100 \mathrm{~h})$. This is noteworthy, because the microstructure of the sample aged for $24 \mathrm{~h}$ at $1273 \mathrm{~K}$ exhibited no rafts. Thus, it can be concluded that the ageing treatment and the respective annealing is responsible for the decrease of the peening-induced hardness, and not the process of rafting.

\section{$\underline{X \text {-ray peak profiles }}$}

Two shot-peened samples were investigated by microfocus and "conventional" high-resolution X-ray diffraction, respectively, one before and one after an ageing treatment ( $24 \mathrm{~h}$ at $1323 \mathrm{~K}$ ). The samples were cut parallel to a $\{100\}$ lattice plane (which was parallel to the rod axis) which is called (100) in the following, and perpendicular to the [001] rod axis. The normal of the peened surface was parallel to [010]. In the following sections, the results are presented, divided into peak position (macrostresses), peak broadening (deformation) and internal strains (microstresses).

Peak position The centres of gravity of the peak profiles are a measure of the peening-induced macrostresses. The results of the measurements of (004) and (400) peak profiles obtained on a peened sample (without ageing treatment) are shown in Fig. 6. These two sets of investigations were measured with the focused synchrotron

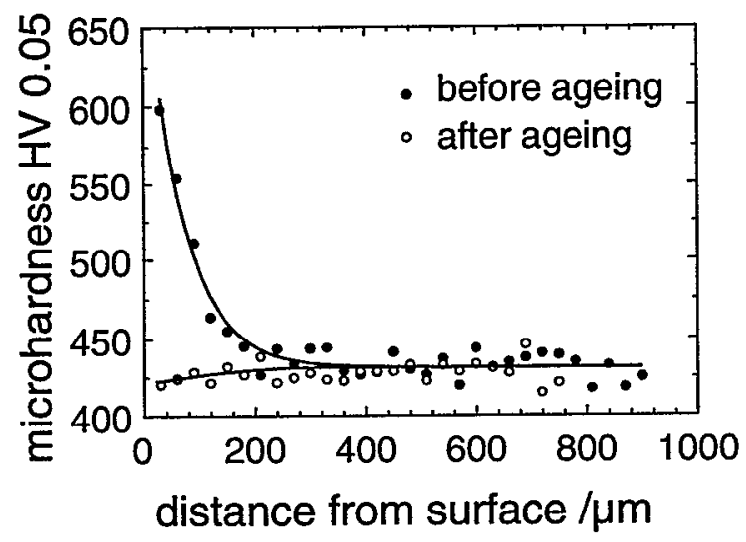

Figure 5: Microhardness after Vickers (HV0.05) for peened samples before and after ageing ( $24 \mathrm{~h}$ at $1323 \mathrm{~K}$ ) vs. distance from the surface.

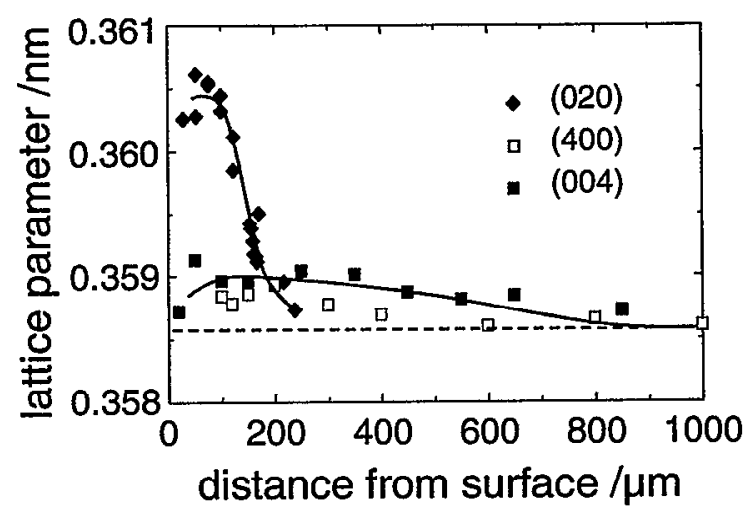

Figure 6: Local variation of the centres of gravity of the peak profiles (004) and (400) measured with synchrotron radiation X-ray diffraction and (020) measured with a home-lab double-crystal diffractometer. The dashed line indicates the stress-free lattice parameter.

radiation $\mathrm{X}$-ray diffraction technique. The two Bragg reflections (004) and (400) are equivalent to another with respect to the stress state: Both reflections indicate the distribution of lattice parameters which have an orientation perpendicular to the normal of the shotpeened surface (which has an orientation of $(010)$ ). Therefore, it is not surprising that the results of the two Bragg reflections (004) and (400) shown in Fig. 6 are in good agreement. In contrast, the peak profiles of the type (020) (measured on the "conventional" double-crystal diffractometer) were measured on a tangential cut of the sample, thus yielding the lattice parameter distribution normal to the surface of the peened sample. In the shot-peened and aged sample, however, significant deviations of the centres of gravity from the stress-free state of undeformed material (dashed in Fig. 6) were not observed.

Peak broadening Fig. 7 shows the variation of the integral breadths of the X-ray peak profiles obtained on the sample without ageing, indicating the strong increase which is due to the plastic deformation induced by the peening treatment. As in the case of the microhardness tests, the increase of the integral breadths was found to occur in a region extending up to $200 \mu \mathrm{m}$ from the surface. The peak profiles were nearly symmetrical without a significant separa-

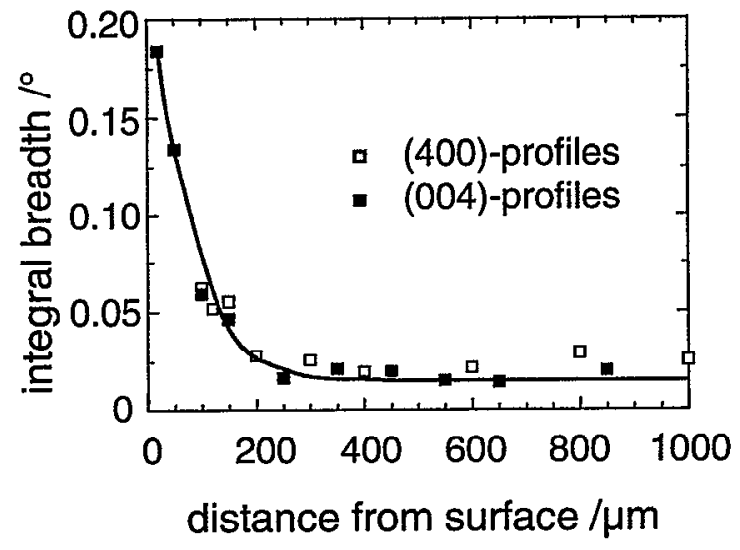

Figure 7: Integral breadth of X-ray peak profiles of a shot-peened sample before ageing vs. distance from the surface, nickel-base superalloy CMSX-6. 
tion into the subprofiles of $\gamma$ and $\gamma$. The peak profiles of the aged sample, however, showed no significant broadening, but a strong separation into the subprofiles of $\gamma$ and $\gamma^{\prime}$, as described in the next section. Therefore, the peak broadening of the aged sample is not shown here.

Internal strains The peak profiles of the shot-peened sample before ageing could not be separated into the subprofiles of $\gamma$ and $\gamma^{\prime}$, as mentioned above. Therefore, only results obtained on the peened and aged sample ( $24 \mathrm{~h}$ at $1323 \mathrm{~K}$, the microstructure is shown in Fig. 4) are presented in the following.

The main results obtained on the aged sample by microfocus $\mathrm{X}$-ray diffraction are shown in Fig. 8. In the interior, a constant lattice parameter was determined for both phases $\gamma$ and $\gamma^{\prime}$. The peak profiles were nearly symmetrical, in agreement with peak profiles of undeformed material of the superalloy CMSX-6. Towards the surface, a separation of the (400) and (004) profiles was obtained, with a larger peak corresponding to $\gamma^{\prime}$ and a smaller peak corresponding to $\gamma$. The lattice parameter values of $\gamma$ increase and those of $\gamma^{\prime}$ decrease with decreasing distance from the surface, respectively. The relevant changes of the lattice parameters in the directions [001] and [100] occur in that region of the sample in which a rafted microstructure was obtained (see Fig. 4).

\section{Mechanical behaviour}

In most cases, in which the phenomenon of anomalous rafting was described $[7,8,10,11]$, the relevance of this microstructural transformation for the mechanical behaviour remained unclear. Therefore, in the present work, the effect of this kind of rafting was investigated in more detail. In particular, it was of interest whether a rafted surface layer has effects on the mechanical high-temperature properties under fatigue and creep loading.

Fatigue lives Cyclic deformation curves of the samples tested at the larger total strain range of $\Delta \varepsilon_{t}=0.01$ are shown in Fig. 9. As reference, sample $A$ was tested in the initially untreated (fully heat-treated) state. The shot-peened sample $C$ which was not aged at all exhibits a clearly shorter fatigue life compared to the reference sample. However, the peened and aged sample $\mathrm{E}$ with an

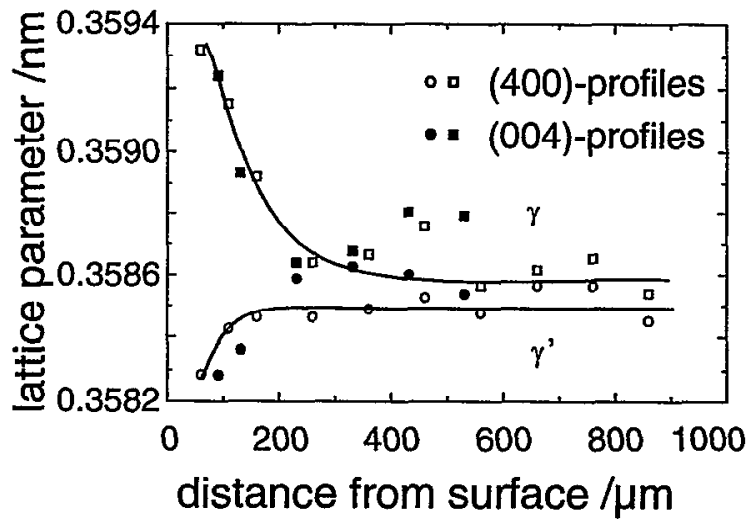

Figure 8: Variation of the lattice parameter values of $\gamma$ and $\gamma^{\prime}$ of a peened and aged sample in the directions [001] and [100] (ageing conditions: $24 \mathrm{~h}$ at $1323 \mathrm{~K}$ ).

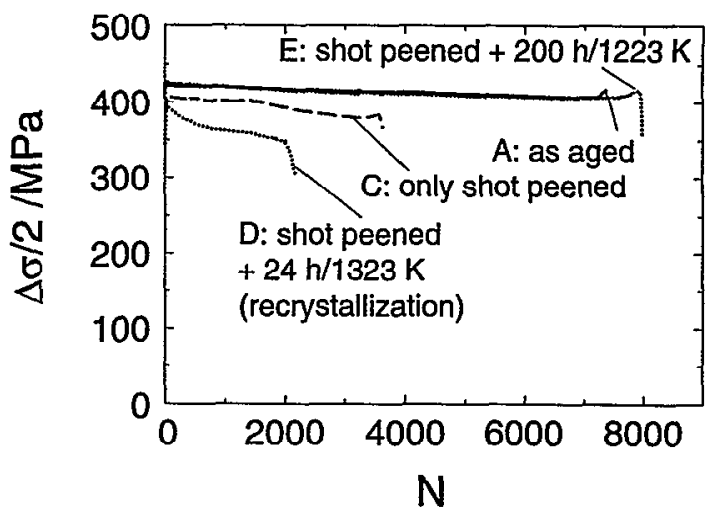

Figure 9: Cyclic deformation curves of the stress amplitude $\Delta \sigma / 2$ vs. number of cycles $\mathrm{N}$ for the samples tested at a temperature of $1223 \mathrm{~K}$ at the larger total strain range of $\Delta \varepsilon_{\mathrm{t}}=0.01$. After [15].

"anomalous" raft structure (ageing for $200 \mathrm{~h}$ at $1223 \mathrm{~K}$ ) showed a cyclic deformation curve and a fatigue life comparable to the reference sample. A comparable result was also obtained in the fatigue tests performed at the smaller strain range. It has to be noted that the recrystallized surface layers of these samples were totally removed by electropolishing before the fatigue tests.

It is also clear from figure 9 that sample $D$ which still had a recrystallized surface layer which was not removed totally by polishing showed the shortest fatigue life. A network of cracks had formed on the surface of this sample along the grain boundaries. Thus, the short fatigue life is well understood as a consequence of the surface grain structure.

Creep strength Creep curves of three different samples are plotted in Fig. 10 as the plastic creep rate $\dot{\varepsilon}_{\mathrm{pl}}$ versus the plastic strain $\varepsilon_{\mathrm{pl}}$. The creep behaviour of one of the peened and aged samples $(24 \mathrm{~h}$ at $1323 \mathrm{~K}$ ) is clearly worse than the creep behaviour of the reference material. The peened sample aged for $200 \mathrm{~h}$ at $1223 \mathrm{~K}$ shows a lower minimum creep rate, but then a faster creep acceleration after the minimum than the reference sample. The times to a strain of $3 \%$ were shorter in both aged samples compared to the reference sample.

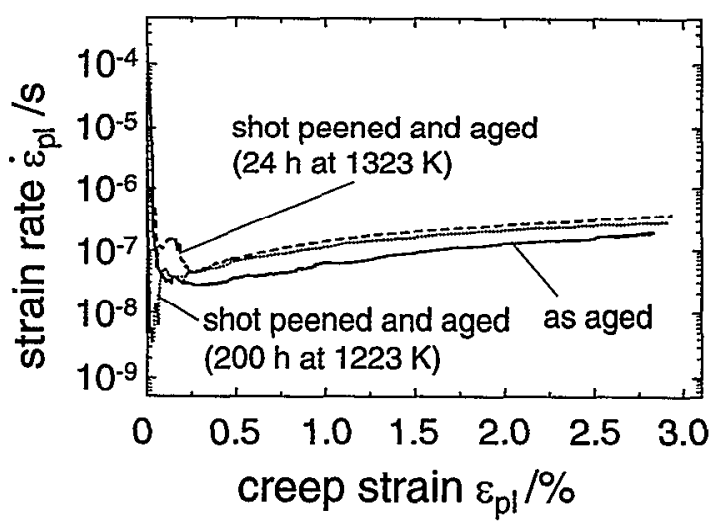

Figure 10: Creep curves of samples of the nickel-base superalloy SRR 99 in the as aged condition and after shot peening and ageing, respectively, for deformation at $\sigma=200 \mathrm{MPa}$ and $\mathrm{T}=1273 \mathrm{~K}$, cf.[15]. 


\section{Discussion}

\section{Origin of anomalous rafting}

The experimental results obtained on the different samples concerning the origin of anomalous rafting can be summarized as follows:

1. Anomalous rafting was repeatedly obtained in turbine blades after scrvicc. However, the occurrence in different turbine blades seems to be unsystematical.

2. Anomalous rafting was observed already in the unused state of an aluminide-coated turbine blade.

3. After ageing of sections of an unused turbine blade, anomalous rafting was found to be very pronounced. However, the rafted zone was obtained only on one side of the blade.

4. In shot-peened specimens, a phenomenon similar to anomalous rafting in turbine blades was observed after ageing under appropriate conditions (high temperature above $1173 \mathrm{~K}$ ).

5. The region in which anomalous rafting was observed in the shot-peened samples was correlated to the region in which severe plastic deformation was evidenced by the measurement of X-ray peak broadening and an increase of microhardness.

6. In a surface layer of shot-peened samples, a complex stress state was determined, indicating biaxial compressive stresses acting parallel to the surface.

These observations can be explained in two ways: i) A first hypothesis is that the modification of the internal microstress state between $\gamma$ and $\gamma^{\prime}$ by plastic deformation is responsible for the microstructural transformation occurring during subsequent ageing treatments at sufficiently high temperatures. ii) The second hypothesis is that the deformation of a surface layer induces a complex state of residual macrostresses which act as driving force for anomalous rafting during a subsequent ageing treatment. In the following, these two possibilities are discussed.

Deformation-induced long-range internal microstresses There are several hints indicating that the internal microstresses induced by plastic deformation are the driving force for anomalous rafting. These long-range internal microstresses have been repeatedly shown to cause rafting, at least in laboratory samples after uniaxial deformation. The most significant examples are the experiments of Véron et al. [3,4] and Fährmann et al. [5]. These two research groups observed that rafting occurred in a predeformed sample during a subsequent stress-free ageing treatment in the manner which one would expect for the sense of predeformation. Even in a case, in which a plastically predeformed sample was subsequently aged under the action of a stress with the opposite sign compared to the predeformation, rafting was determined by the preceding plastic deformation process [5]. Also in the case of thermomechanical fatigue experiments, the sense of the plastic strain (and therefore the change of the internal microstress state) and not the external stress has been shown to determine the occurring type of rafting [6].

In the case of the present work, this possible origin for rafting can explain all discussed cases: Turbine blades are surface treated by grit blasting or shot peening before the coating process. This procedure will probably cause plastic deformation of a surface layer.
It has to be noted that this treatment is not always systematically applied, since it is performed in some cases only when necessary, and sometimes the surfaces are treated manually. Subsequently, at the high temperature occurring during the coating procedure, a first rafting process can occur, see the micrograph of an unused turbine blade in Fig. 1. Finally, after service at sufficiently high temperatures applied for some time, rafting will inevitably occur under the surfaces with an "anomalous" orientation of the $\gamma / \gamma$ ' plates parallel the surfaces, whereas the "normal" rafting process will occur in the interior of the material perpendicular to the cxternal [001] stress axis.

With this explanation, it can be understood why the anomalous rafting was found only in one of the operated turbine blades: That turbine blade had probably a pretreatment which was more severe and which therefore induced (more) plastic deformation, leading to anomalous rafting during service. This would explain the observations on the aged sections of the unused turbine blade: These seclions had only one side which showed "anomalous" rafts. The reason is probably that only this side was treated severely enough to induce anomalous rafting, and the other side was treated less severely.

The lattice parameter changes between $\gamma$ and $\gamma^{\prime}$ observed after rafting (shown in Fig. 8) are finally a consequence of cooling to room temperature after ageing and can be explained as follows: During the ageing treatment (i.e. during rafting) the two phases $\gamma$ and $\gamma^{\prime}$ were at high temperature and, because of the dynamic transformation of the morphology, tended to reduce their elastic strain cnergy. It can thercfore be assumed that the two phases were approximately free of stresses after completion of the rafting procedure. During cooling, the plates of the two phases were contracted thermally. Due to the difference of the coefficients of thermal expansion of the two phases $\gamma$ and $\gamma^{\prime}$, the plates would separately experience different thermal contraction strains. However, there is a strong constraint in the material, and thermally-induced internal microstresses arise. Similar thermally-induced microstresses and -strains have experimentally been observed in rafted creep-deformed samples [20] and calculated by finite element modelling [21].

There exists at present no micromechanical plasticity model which explains how the anomalous rafting is induced as a consequence of plastic deformation (and the change of the internal microstresses) by e.g. shot peening. In order to formulate such a model, transmission electron microscopic investigations of the respective zone of potential anomalous rafting before ageing will be necessary.

Shot-peening induced macrostresses As a second possibility, the peening-induced macrostresses have to be discussed. These internal stresses are known to be of biaxial compressive character acting parallel to a peened surface [22]. The investigation of the peened, but unaged sample by $\mathrm{X}$-ray diffraction (Fig. 6) indicates the presence of such a complex stress state under the surface of the sample. The large increase of the lattice parameter in the [010] direction (i.e. parallel to the surface normal) is the corresponding Poisson strain of the peening-induced macrostresses. The measured increase of the lattice parameters in the directions [100] and [001] parallel to the surface plane cannot be fully explained in the present work. A possible reason for this increase is the relaxation 
of the large peening macrostresses during cutting of the peened specimen. As an example, on the (010) surface, the peening compressive macrostresses act in the directions [100] and [001]. During preparation, the sample was cut parallel to the (100) plane. Then, the stress acting in [100] direction is relieved, and only the compressive stress acting in the [001] direction remains. As a consequence, this stress will increase the lattice parameter in the [100] direction by the Poisson strain. A similar effect occurs in the case of a (001) cut.

Now, it shall be discussed how the peening-induced macrostresses could cause the observed cases of anomalous rafting. Under the assumption that during surface treatments like peening or grinding compressive stresses arise, we can compare the effect of these biaxial compressive stresses with the distortion induced by an external tensile stress acting in the normal direction on the surface of peened material. Such a tensile stress, however, is known to induce in alloys of negative lattice misfit (like SRR 99 and CMSX-6 which have a negative lattice misfit at the high service temperatures $[8,20]$ ) rafts perpendicular to this (tensile) stress state [1]. Thus, the anomalous rafts could also be explained by biaxial compressive stresses acting under a mechanically treated surface.

However, there is an argument against this hypothesis. Khadhraoui et al. investigated experimentally and by modelling the relaxation of shot-peening residual stresses [22]. After ageing for up to $100 \mathrm{~h}$ at temperatures of $873 \mathrm{~K}$ and $923 \mathrm{~K}$, a strong recovery of the peening stresses up to $50 \%$ of the initial value was reported. This result makes the peening-induced macrostresses as the driving force for anomalous rafting improbable, because the temperatures necessary for rafting are much higher than those applied by Khadhraoui et al. [22]. Therefore, the peening-induced macrostresses will probably vanish early during the ageing treatment.

In addition, the microstructural results obtained on the sample with a removed surface layer of $50 \mu \mathrm{m}$ indicate that the peening-induced macrostresses are of minor relevance. The effect of "anomalous rafting" ubserved in this sample was similar to that observed in the other samples aged at comparable conditions. However, it can be assumed that the peening-induced macrostresses were substantially modified and decreased by the removal of a layer of $50 \mu \mathrm{m}$. Therefore, the macrostresses seem to be of minor importance for "anomalous" rafting.

The fact that the mean lattice parameters of the peened and aged sample with "anomalous" rafts indicate a macroscopically stressfree state does not give an answer to the question whether the peening-induced micro- or macrostresses were the origin for anomalous rafting. The investigated sample corresponds to the already rafted microstructure which is not expected to contain macrostresses.

As a summary of the two possible origins of anomalous rafting, we conclude that it seems to be more probable from the presented results that the effect of anomalous rafting is induced by a mechanical surface treatment, at least in those cases discussed in this work. The specific question whether the microstresses acting between $\gamma$ and $\gamma^{\prime}$ or the peening-induced macrostresses were the main driving forces for the microstructural transformation cannot be answered finally. Nevertheless, there are strong hints that the microstresses are the responsible microstructural reason for anomalous rafting.

\section{Anomalous rafting during engine operation}

The results of the present work on anomalous rafting in turbine blades seem different from earlier observations. Draper et al. [7] observed anomalous rafting under the surface of uncoated, monocrystalline turbine blades after a "performance test" (P) and after a "high cycle fatigue test" (cycle A) or after combinations of other tests with one of these two test conditions during ground-based engine tests. Both test conditions (P) and (A) consist of stepwise varying power settings between idle and cruise power levels. After other test cycles, e.g. constant operation at maximum temperature ("stress rupture, cycle B"), "Iow cycle fatigue, cycle C" or a "mission mix, cycle D", or combinations of these, no anomalous rafting was found, although, in some cases, normal rafting occurred. The authors discuss that anomalous rafting is caused by a "complex stress state at the surface of the blade" during the respective tests which stems from blade resonant conditions at an intermediate power level.

In the present case, however, it is clear that the ohserved rafting is caused by other processes: i) We have investigated coated blades which were peened before the coating procedure. ii) In the unused blade before as well as after the (stress-free) ageing treatment, the blades had not been subjected to engine operation at all. In the blade operated in an accelerated mission test, a test condition similar to the "stress rupture test, cycle B" of Draper et al. was applied. However, in contrast to the results of Draper et al., we observed anomalous rafting after operation under this condition.

These reasons indicate that, at least in the present case, the origin of anomalous rafting is not the operation condition in the test engine. In addition, the present observation of anomalous rafting on only one side of the aged blade shows that the reason seems to be in some way unsystematical.

\section{Recrystallization}

The ageing treatments applied to the shot-peened samples yield interesting results on the recrystallization behaviour of nickel-base superalloy single crystals. The appearance of recrystallization is very similar to the cellular recrystallization described earlier [23,24] (see also the recent work of Bürgel et al. [25] on the origin of recrystallization in superalloys). Recrystallization could not be avoided by the application of a drastically reduced heating rate ( $50 \mathrm{~K}$ per hour) and a holding time during heating ( $2 \mathrm{~h}$ at $1073 \mathrm{~K}$ ). Therefore, the recovery occurring during the slow heating and the holding time at $1073 \mathrm{~K}$ were not sufficient to reduce the driving force for recrystallization. Furthermore, it has to be noted that the removal of the surface roughness by electropolishing did also not influence recrystallization.

However, recrystallization could be largely avoided in one sample, from which a surface layer of $50 \mu \mathrm{m}$ was removed by polishing. This is worth mentioning, because $\mathrm{X}$-ray peak broadening (Fig. 7) and microhardness investigations (Fig. 5) showed the zone of plastic deformation to have a depth of about $200 \mu \mathrm{m}$. It can be concluded from this observation that there is a critical deformation oc- 
curring in the outer $50 \mu \mathrm{m}$ which is necessary for recrystallization in the nickel-base superalloy SRR 99. At lower deformation levels, no recrystallization was obtained.

\section{Effect of anomalous rafting on the mechanical behaviour}

Fatigue Recently, Mughrabi et al. showed that samples with a rafted microstructure with an orientation of the $\gamma / \gamma^{\prime}$ plates parallel to the stress axis (induced by compressive predeformation) have increased life times under isothermal high-temperature fatigue loading than the initial microstructure with cuboidal $\gamma^{\prime}$ particles $[2,12]$. Such an effect was an original motivation for the present work. However, the thickness of the rafted layer induced by shot peening and ageing was only about $100 \mu \mathrm{m}$. The cyclic deformation curves are identical for the reference samples with cuboidal $\gamma^{\prime}$ precipitates and for the samples with a rafted surface layer (the deformation curves obtained with the higher applied strain range are shown in Fig. 9). It can therefore be concluded that this zone is not thick enough to influence the mechanical behaviour or the fatigue life of the total sample appreciably.

The fatigue lives of the peened samples $C$ (only peened) and $D$ (peened and aged, but with recrystallized grains) were significantly shorter than the fatigue life of the reference material. This is partially in contrast to results obtained earlier [24]. However, a reason for this difference cannot be given yet.

Creep The increase of the creep rate in the case of the aged samples is due to the deterioration of the creep resistance caused by coarsening of the microstructure in the bulk of the samples, similar to the results obtained by Mughrabi et al. on aged samples [13-15]. The enhancement reported by the authors for the case of samples which had a $\gamma / \gamma^{\prime}$ raft structure parallel to the tensile deformation axis in the whole specimen induced by compressive predeformation was not obtained in the present samples with a thin surface layer of similar rafts. The reason is that the area fraction of rafted material with respect to the total cross section is small, and a possible enhancing effect is overcompensated by the deterioration due to the coarsening effect in the bulk.

Microhardness The investigations of the peened and aged samples by microhardness testing yield information on the room temperature strength of the different microstructures. The values obtained on the differently aged samples, however, were equal within some scatter. Only a small decrease of the microhardness was found in the rafted region which was smaller than the scatter. Therefore, it cannot be considered significant.

\section{Conclusions}

The phenomenon of anomalous rafting was investigated in real turbine blades and in shot-peened laboratory samples by scanning electron microscopy, microhardness testing and high-resolution $\mathrm{X}$ ray diffraction. From the results, conclusions were drawn on the origin of this microstructural transformation. In addition, the effect of anomalous rafting on the mechanical high-temperature properties was investigated in fatigue and creep tests. The following conclusions can be drawn:

1. Anomalous rafts were obtained in aluminide-coated turbine blades of the nickel-base superalloy CMSX-6 before and after service. In addition, this kind of rafting was observed after ageing of unused sections of a turbine blade.

2. A similar effect was found in shot-peened samples of the superalloy SRR 99 after shot-peening and ageing.

3. Two different possibilities were discussed to explain anomalous rafting: deformation-induced internal microstresses acting between the two phases $\gamma$ and $\gamma^{\prime}$ and compressive macrostresses, respectively. Experimental results indicate that the internal microstresses are the main driving force for rafting.

4. A layer of rafts with an orientation parallel to the surface (i.e. anomalous rafts induced by shot peening and subsequent ageing) is more or less indifferent for the fatigue strength and life time.

5. The creep behaviour is not affected by thin surface layer of anomalous rafts.

6. Recrystallization of shot-peened samples can only be avoided by the removal of the highly deformed outer surface layer, not by recovery during a heating procedure. However, it is not necessary to remove the whole plastically deformed material to avoid recrystallization in the case of the nickel-base superalloy SRR 99.

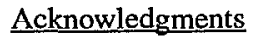

The authors thank Dr.-Ing. D. Goldschmidt (formerly MTU, Munich, now Siemens AG/KWU, Mülheim), and the company MTU for providing the investigated turbine blades. The authors are grateful to V. Schulze, Institut für Werkstoffkunde I, Universität Karlsruhe, for shot-peening, to A. Snigirev, A. Souvorov and M. Drakopoulos, ESRF, Grenoble, for their competent technical assistance at the microfocus X-ray experiments performed at the optics beam-line (BM 5/ID 10) and to K. Zinn, Institut WTM, Universität Erlangen-Nürnberg, for microhardness testing. Parts of this work were supported by Deutsche Forschungsgemeinschaft (Mu502/ 12), by Volkswagen-Stiftung (I/69362), and by ESRF, Grenoble.

\section{Literature}

1. F.R.N. Nabarro, "Rafting in Superalloys", Metall. Mater. Trans., 27A (1996), 513-530.

2. H. Mughrabi, " $\gamma / \gamma^{\prime}$ Rafting and its Effect on the Creep and Fatigue Behaviour of Monocrystalline Superalloys", in The Johannes Weertman Symposium, eds. R.J. Arsenault, D. Cole, T. Gross, G. Kostorz, P.K. Liaw, S. Parameswaran and H. Sizek, (Warrendale: PA, The Minerals, Metals and Materials Society, 1996), 267-278.

3. M. Véron, Y. Bréchet, and F. Louchet, "Directional Coarsening of Nickel Based Superalloys: Driving Force and Kinetics", in Proc. 8th Int. Symp. on Superalloys (Superalloys 1996), eds. R.D. Kissinger, D.J. Deye, D.L. Anton, A.D. Cetel, M.V. Nathal, T.M. Pollock and D.A. Woodford, (Warrendale, PA: The Minerals, Metals and Materials Society, 1996), 181-190.

4. M. Véron and P. Bastie, "Strain Induced Directional Coarsening in Nickel Based Superalloy: Investigation on Kinetics using Small Angle Neutron Scattering (SANS) Technique", Acta mater., 45 (1997), 3277-3282. 
5. M. Fährmann, E. Fährmann, O. Paris, P. Fratzl, and T.M. Pollock, "An Experimental Study of the Role of Plasticity in the Rafting Kinetics of a Single Crystal Ni-Base Superalloy", in Proc. 8th Int. Symp. on Superalloys (Superalloys 1996), eds. R.D. Kissinger, D.J. Deye, D.L. Anton, A.D. Cetel, M.V. Nathal, T.M. Pollock and D.A. Woodford, (Warrendale, PA: The Minerals, Metals and Materials Society, 1996), 191-200.

6. S. Kraft, I. Altenberger and H. Mughrabi, "Directional $\gamma / \gamma$ ' Coarsening in a Monocrystalline Nickel-Based Superalloy during Low-Cycle Thermomechanical Fatigue", Scripta metall. mater., 32 (1995), 411-416, and Scripta mctall. mater., 32 (1995), 1903 (Erratum).

7. S. Draper, D. Hull and R. Dreshfield, "Observations of Directional Gamma Prime Coarsening during Engine Operation", Metall. Trans., 20A, (1989), 683-688.

8. B. von Grossmann, "Mikrostrukturelle Bestimmung der lokalen Belastungen in einkristallinen Turbinenschaufeln aus Nickelbasis-Superlegierungen" (Doctorate Thesis, Universität Erlangen-Nürnberg, 1998, Aachen, Germany: Shaker Verlag, 1999).

9. H. Biermann, B. von Grossmann, T. Schneider, H. Feng and H. Mughrabi, "Investigation of the $\gamma / \gamma$ ' Morphology and Internal Stresses in a Monocrystalline Turbine Blade after Service: Determination of the Local Thermal and Mechanical Loads", in Proc. 8th Int. Symp. on Superalloys (Superalloys 1996), eds. R.D. Kissinger, D.J. Deye, D.L. Anton, A.D. Cetel, M.V. Nathal, T.M. Pollock and D.A. Woodford, (Warrendale, PA: The Minerals, Metals and Materials Society, 1996), 201-210.

10. P. Moretto and J. Bressers, "Thermo-Mechanical Fatigue Degradation of a Nickel-Aluminide Coating on a SingleCrystal Nickel-Based Alloy", I. Mat. Sci., 31 (1996), 48174829.

11. J. Bressers, D.J. Arrell, K.M. Ostolaza and J.L. Vallés, "Effect of an Aluminide Coating on Precipitate Rafting in Superalloys", Mater. Sci. Engng A, 220 (1996), 147-154.

12. M. Ott, U. Tetzlaff and H. Mughrabi, "Influence of Directional Coarsening on the Isothermal High-Temperature Fatigue Behaviour of the Monocrystalline Nickel-Base Superalloys CMSX-6 and CMSX-4", in Microstructure and Mechanical Properties of Metallic High-Temperature_Materials, eds. H. Mughrabi, G. Gottstein, H. Mecking, H. Riedel and J. Tobolski, (Weinheim: Wiley-VCH, 1999), 425-440.

13. H. Mughrabi and U. Tetzlaff, "Microstructure and HighTemperature Strength of Monocrystalline Nickel-Base Superalloys", Adv. Eng. Mater., (2000), in print.

14. U. Tetzlaff, M. Nicolas and H. Mughrabi, "Can the High Temperature Tensile Strength of Nickel-Base Superalloys be Improved by Pre-Rafting?", in Proc. EUROMAT '9g, Vol. 10, eds. D.G. Morris et al., (Weinheim: Wiley-VCH, 2000), in print.
15. U. Tetzlaff, "Gezielte gerichtete Vergröberung (Floßbildung) des $\gamma / \gamma$-Gefüges und Auswirkungen auf die mechanischen Hochtemperatureigenschaften einkristalliner Nickelbasis-Superlegierungen (Doctorate Thesis, Universität ErlangenNürnberg, 2000).

16. H. Biermann, U. Tetzlaff, B. von Grossmann, H. Mughrabi and V. Schulze, "Rafting in Monocrystalline Nickel-Base Superalloys induced by Shot Peening", Scripta mater, accepted for publication.

17. H.-A. Kuhn, H. Biermann, T. Ungár and H. Mughrabi, "An Xray study of creep-deformation induced changes of the lattice mismatch in the $\gamma^{\prime}$-hardened monocrystalline nickel-base superalloy SRR 99", Acta metall. mater., 39 (1991), 2783-2794.

18. H. Biermann, B. von Grossmann, S. Mechsner, H. Mughrabi, T. Ungár, A. Snigirev, I. Snigireva, A. Souvorov, M. Kocsis and C. Raven, "Microbeam Synchrotron Radiation Diffraction Study of a Monocrystalline Nickel-Base Turbine Blade after Service", Scripta mater., 37 (1997), 1309-1314.

19. H. Biermann, B. von Grossmann, T. Ungár, S. Mechsner, A. Souvorov, M. Drakopoulos, A. Snigirev and H. Mughrabi, "Determination of Local Strains in a Monocrystalline Turbine Blade by Microbeam X-ray Diffraction with Synchrotron Radiation", Acta mater., 48 (2000), 2221-2230.

20. H. Biermann, M. Strehler and H. Mughrabi, "High-Temperature Measurements of Lattice Parameters and Internal Stresses of a Creep-Deformed Monocrystalline Nickel-Base Superalloy", Metall. Trans. A, 27A (1996), 1003-1014.

21. H. Feng, H. Biermann and H. Mughrabi, "3D Finite Element Modelling of Lattice Misfit and Long-Range Internal Stresses in Creep-Deformed Nickel-Base Superalloy Single Crystals", Mater. Sci. Engng. A, 214 (1996), 1-16.

22. M. Khadhraoui, W. Cao, L. Castex, and J.Y. Guédou, "Experimental Investigations and Modelling of Relaxation Behaviour of Shot Peening Residual Stresses at High Temperature for Nickel Base Superalloys", Mat. Sci. Technol., 13 (1997), 360-367.

23. S.D. Bond and J.W. Martin, "Surface Recrystallization in a Single Crystal Nickel-Based Superalloy", J. Mater. Sci., 19 (1984), 3867-3872.

24. P. D. Portella and W. Österle, "Influence of Cellular Rccrystallization on the Fatigue Behaviour of Single Crystal NiBased Superalloys", in Microstructure and Mechanical Properties of Metallic High-Temperature Materials, eds. $H$. Mughrabi, G. Gottstein, H. Mecking, H. Riedel and J. Tobolski, (Weinheim: Wiley-VCH, 1999), 441-453.

25. R. Bürgel, P.D. Portella and J. Preuhs, "Recrystallization in Single Crystals of Nickel Base Superalloys", in Proc. 9th Int. Symp. on Superalloys (Superalloys 2000), (Warrendale, PA: The Minerals, Metals and Materials Society, 2000), this volume. 